\title{
Tierra, agroindustria y transgénicos: Conflictos sociales populares en la Bolivia de la Madre Tierra
}

\author{
Land, agroindustry and transgenics: Popular social conflicts in \\ the Bolivia of Mother Earth
}

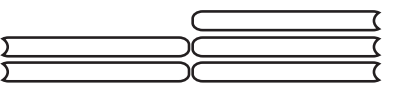

Nohely Guzmán N. ${ }^{1}$

Recibido: enero 2017 Aprobado: junio 2017

\section{Resumen}

Este artículo analiza los complejos y abigarrados procesos de lucha social-popular boliviana alrededor de la tierra, y la negociación de esta entre las élites agroindustriales y el actual gobierno. En este, se aborda la problemática de los transgénicos y su vertiginosa expansión en las tierras productivas del territorio nacional a partir del sistemático avasallamiento de tierras y derechos, que respaldados por el Estado, reproducen y consolidan el viejo orden de dominación y su estructura patrimonialista de uso y tenencia de la tierra. El presente artículo regresa la mirada sobre la resistencia a los transgénicos y las luchas por la tierra como condiciones de producción y reproducción de la vida.

Palabras clave: Tierra, agroindustria, luchas y resistencias, soya transgénica, Bolivia.

\begin{abstract}
This a rticle a nalyzes the complex p rocesses of B olivian s ocialpopular struggle around the land, and the negotiation of it between the agroindustrial elites and the current government. Here, the problem of genetically modified organisms and its vertiginous expansion into productive lands of the national territory began from the systematic subjugation of lands and rights, supported by the State, which has reproduced and consolidated the former order of domination and its patrimonialistic structure of land use and land ternure. The article looks back at the resistance to genetically modified organisms and the struggles for land as conditions of production and reproduction of life.
\end{abstract}

Keywords: Land, Agroindustry, Struggles and resistance, Genetically modified Soy, Bolivia.

1 Foro Boliviano sobre Medio Ambiente y Desarrollo (FOBOMADE). nohelygn@gmail.com 


\section{Ritmo sociopolítico: Luchas y demandas}

En el 2005, tras ocho años de resistencia, fue aprobada la soya transgénica en Bolivia. Este proceso que comenzó en 1997 y continúa hasta la actualidad, encierra en sí mismo un complejo entramado de luchas sociales. La agricultura mecanizada de cultivos comerciales - de los que la soya es el principal cultivo- representa la mayor causa de deforestación en el país (CIFOR, 2014). Actualmente, "un $75 \%$ de la producción de soya se realiza en propiedades mayores a 50 hectáreas" (CIFOR, 2014, p. 12), la mayoría de estas en manos de empresas agroindustriales controladas por pequeños grupos empresarios cruceños, que, con una importante influencia de empresas internacionales y capital extranjero, ponen en evidencia el juego de poderes y negociaciones asociados a los intereses detrás de los transgénicos: una de las principales demandas del agronegocio.

La historia de Bolivia y las luchas que han marcado esta misma se han constituido, desde sus orígenes, en dos pilares fundamentales: tierra y autogobierno. Estos, en tanto componentes reivindicatorios esenciales de las luchas populares, han asumido diversos nombres y facetas que han estructurado una Bolivia caracterizada por la rebeldía, la insurgencia, y la no negociabilidad de aquellos elementos que configuran las formas de producción y reproducción de la vida.

Probablemente, uno de los periodos que refleja con mayor claridad aquello es el que va de 2000 a 2005, pues contuvo importantes levantamientos solo equiparables a los suscitados en la Guerra Federal (1899) y la Revolución del 1952, que, a pesar de poseer evidentes y enormes diferencias entre sí, tienen en común la tenacidad de la fuerza social que los gestó (Salazar, 2015).

En este periodo, la Guerra del Agua (2000) y la Guerra del Gas (2003) -entre otros procesos ricos en términos de pugna emancipatoria- evidencian, con bastante precisión, el antagonismo entre los objetivos impulsados por el neoliberalismo desde décadas atrás, y las formas de producción y organización social popular boliviana, cuyas fuerzas de resistencia truncaron y derrotaron, en reiteradas ocasiones, el poder de dominación de las élites nacionales y transnacionales (Gutiérrez, 2009). Un claro y paradigmático ejemplo de ello es la expulsión del entonces presidente Gonzalo Sánchez de Lozada (Goni), quien en noviembre de 2003 abandonó el país, desbordado por las movilizaciones de la Guerra del Gas. A raíz de esto, el entonces vicepresidente, Carlos Mesa Quisbert, asume la presidencia del país por un breve periodo de 
aproximadamente 1 año y 8 meses, durante el que, en julio de 2005 autorizó, mediante Decreto Supremo N. ${ }^{\circ} 28225$, la producción y comercialización de soya transgénica resistente al herbicida glifosato en el país.

A este respecto, es importante recordar las resistencias a los transgénicos que años antes a esta autorización habían tenido lugar en el país. Entre estas, se destacan el cerco de más de un mes de duración a la ciudad de La Paz que, organizado el año 2000 por Felipe Quispe ${ }^{2}$, logró detener el proceso de evaluación de solicitudes de transgénicos del Comité de Bioseguridad; y también la gran marcha del año 2002, en la que el departamento de Santa Cruz se organizó contra la aprobación de soya transgénica que se venía impulsando a través de insidiosas interpretaciones legales (Molina, 2011).

En ese momento, y luego de 8 años de resistencia a los insistentes intentos de aprobación de transgénicos en el país, las organizaciones sociales desplegaron múltiples esfuerzos de movilización y protesta, las cuales fueron apoyadas por el entonces diputado -y actual presidente- Evo Morales Ayma, quien en un escenario subversivo acondicionado por estas luchas reivindicatorias -engendradas y maduradas desde abajo y por fuera del Estado-, da lugar a la victoria del actual partido de gobierno.

Dicha victoria, por el contexto social e histórico del momento, se encontraba enmarcada en unas coordenadas sociopolíticas que la situaban como un problema para las clases dominantes que, a juzgar por el discurso político del partido de gobierno en su primer mandato, se verían "desfavorecidas" con su toma de posesión. Sin embargo, para las organizaciones sociales populares, se trataba de un logro simbólico, mas no suficiente para representar una victoria propia, por lo que, desde el comienzo, estas se mantuvieron al margen, con agendas propias y afirmando que "el proceso de cambio, el Pachakuti, continúa, no empieza ni se acaba con el gobierno de Evo Morales" (Salazar, 2015, p. 107).

Así, y dando continuidad a las demandas históricas del sector, dichas organizaciones mantuvieron como su objetivo central la materialización de sus propias perspectivas del nuevo orden sociopolítico que querían construir. A este respecto, y dado que el contenido de las demandas no era restrictivamente considerado facultad del Estado, las organizaciones sociales no se vieron en ningún momento representadas ni contenidas por este, por lo que permanecen y despliegan acciones propias para abrirle un lugar a su agenda,

2 Historiador, político y subversivo dirigente campesino. Uno de los personajes más importantes de la historia de Bolivia. Se le llamó el "Mallku” (“cóndor” en aymara) que simboliza la máxima autoridad comunal. 
que en ese momento significaba la germinación de una serie de procesos complejos que tenían como finalidad la tan disputada reestructuración del sistema político Estatal y su orden de dominación (Tapia, 2011).

En este sentido, las organizaciones sociales se mantuvieron plenamente conscientes de que la victoria del MAS podía representar un importante avance en cuanto a la limitación de poder de las estructuras de dominación histórica, pero tenían, a su vez, muy claro que aquello jamás significó una transferencia directa de sus demandas -y mucho menos sus luchas- al Estado, que era concebido más como un medio de canalización de las demandas, que un fin en sí mismo (Gutiérrez, 2009).

No obstante, este abigarrado proceso social, diverso y heterogéneo, también presentó algunas vacilaciones y contradicciones, las cuales, modificando trascendentalmente sus estrategias -pero no sus fines-, colocaron algunas de sus demandas - particularmente las relacionadas con la tierra- en el plano estatal, con la finalidad de ampliar sus alcances (Salazar, 2015). Sin embargo, es importante destacar que estas vacilaciones no se debían únicamente a la complejidad del proceso, sino también a la fuerza con la que el Estado -desde el principio- intentó subsumir las luchas sociales populares, para reencausarlas dentro del marco de lo estatal.

En este sentido, es importante subrayar que el periodo anteriormente señalado (2000-2005) cobra particular importancia, pues en este se enfatiza y destaca la oligarquía terrateniente boliviana como una de las principales amenazas para las demandas históricas de reivindicación.

\section{Negociaciones y metamorfosis del "proceso de cambio"}

Este marco, que ha tratado de resumir y esbozar los procesos sociopolíticos y sus proyectos para la transformación del país, fue el escenario en que se suscitó el primer quiebre que determinaría las condiciones y posibilidades de subvertir la política agraria del país, y con ella, el ingreso de soya transgénica.

Así, cuando en 2006 - 2007, en el marco de la Asamblea Constituyente, las organizaciones sociales populares demandaron lo que se denominó Reconducción de la Reforma Agraria, el gobierno dio la primera muestra de una transfiguración, que como se desarrollará a continuación, devino en una relación meramente instrumental y de apropiación del discurso y narrativas de las organizaciones sociales populares e indígenas. La respuesta del gobierno a esta demanda fue difusa, pues, por una parte, intentó atenderla y darle respuesta; pero, por otra, la movilización y todavía importante presencia del 
sector oligarca-burgués del oriente -cuya presencia en el parlamento era desequilibrante- significó una importante presión, ante la cual finalmente cedió hasta prácticamente anular la reforma agraria y legalizar las formas de latifundio preexistentes (Ormachea, 2007).

Este nuevo proceso inició con la promulgación de siete decretos denominados de la "revolución agraria" (2006) que intentaban suplir y abordar algunas de las temáticas de la truncada Ley de Reforma Agraria. De estos, el más controvertido fue, sin lugar a duda, el Decreto Supremo N. ${ }^{\circ} 28733$, que reglamentó la dotación de tierras fiscales a grupos indígenas, originarios y campesinado sin tierra -o con tierras insuficientes- que residieran en el lugar. Este, como era de esperarse, generó una serie de tensiones, movilizaciones y protestas, pues, por un lado, el sector agroindustrial repelía por completo dicha medida y, por el otro, las organizaciones sociales populares reconocían la insuficiencia de dichos decretos, exigiendo la aprobación de una Ley de Reconducción de la Reforma Agraria que contemple con mayor profundidad las demandas históricas.

De esta manera, a finales de noviembre del 2006, y a pesar de la fuerte oposición de la vieja élite agroindustrial, la Ley de Reconducción de la Reforma Agraria (Ley N. ${ }^{\circ}$ 3545) fue aprobada, y dio inicio a una nueva fase que avanzaba con pasos firmes hacia su objetivo final: la eliminación del latifundio para la redistribución de tierras. Para esto, se había contemplado, como una condición necesaria, la verificación de la función económica y social de la tierra (FES), en tanto esta era capaz de viabilizar la reversión en caso de no demostrarse su función. Sin embargo, esta precisaba, a su vez, la continuidad paralela del arduo proceso de saneamiento y titulación de tierras, junto al que finalmente se alcanzaría el objetivo final.

Empero, meses después de la aprobación de la Ley de Reconducción de la Reforma Agraria, se evidenciaron una serie de elementos contenidos en ella misma, que obstaculizaron enormemente su efectividad. Dentro de estos, es particularmente relevante la protección que conservó casi intactas las concesiones de tierras entregadas a la oligarquía terrateniente en el marco de las negociaciones previas a la aprobación de la ley que, de igual manera, protegieron casi en su totalidad las propiedades poseídas por estos mismos (Ormachea, 2007). En este sentido, no pueden ser obviados los datos del proceso de saneamiento de tierras, que demuestran cómo este operó particularmente sobre las Tierras Comunitarias de Origen (TCO), y tierras fiscales, dejando así intacta la propiedad de la oligarquía terrateniente (Urioste, 2009). 


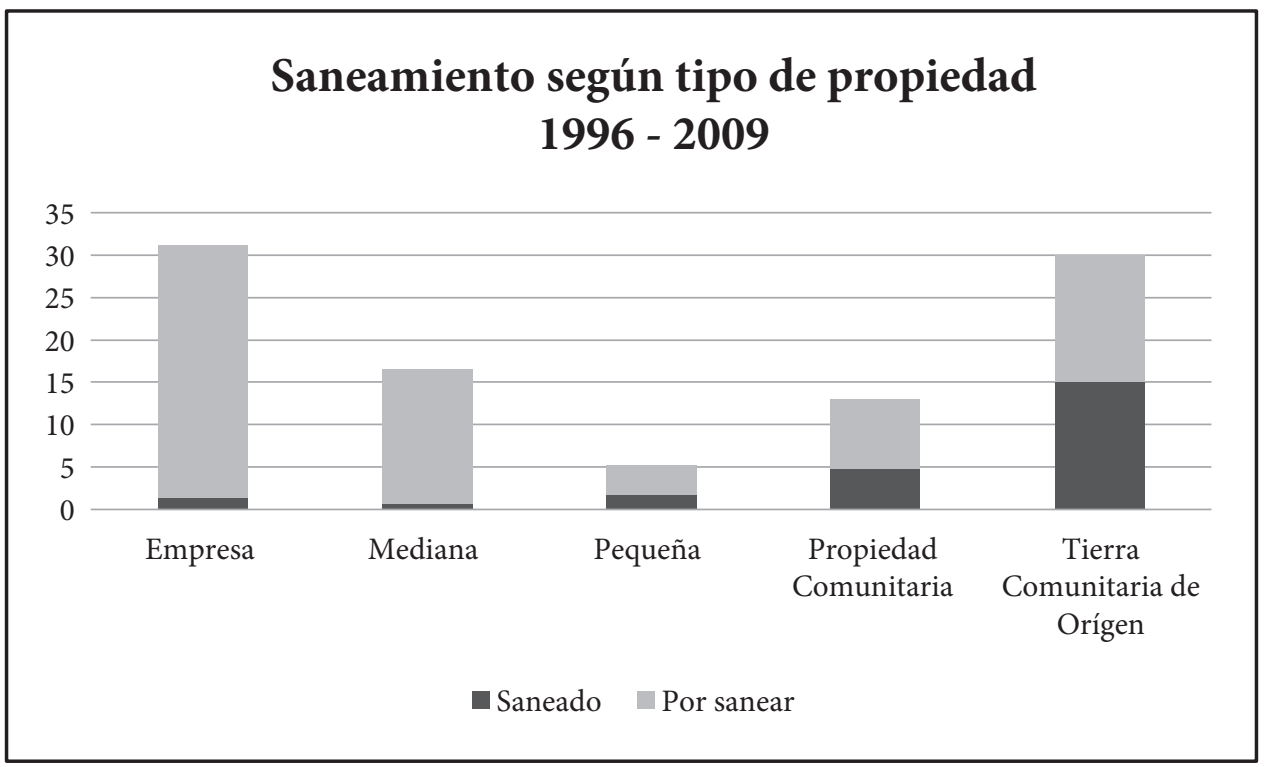

Figura 1. Saneamiento según tipo de propiedad en Bolivia entre 1996 y 2009. Elaboración propia con datos de Urioste (2009).

No obstante, es importante revisar con detenimiento aquellos procesos, pues permiten, por un lado, dar cuenta de que los logros de las demandas realizadas se deben más a la fuerza de las organizaciones sociales, que a la voluntad del Estado y del partido de gobierno; y, al mismo tiempo, comprender las negociaciones entre el Estado y la élite agroindustrial, que se ven reflejadas en una metamorfosis gubernamental que, a nombre de la modernidad, el potenciamiento, y la pujanza del sector, ha puesto en marcha diversas estrategias y modificaciones que lo respaldaron y protegieron.

Asimismo, son estos procesos de negociación los que terminan desplazando las demandas de las organizaciones sociales populares, aspecto que es más evidente en el proceso constituyente, en el que claramente se desarrolla una reestructuración con base en las alianzas con sectores económicos de importancia, entre ellos, el agroindustrial.

De esta manera, el proceso constituyente dio paso a otra gran victoria para el grupo de poder hacendal con la aprobación del Art. 399 de la actual Constitución Política del Estado Plurinacional de Bolivia (CPE), el cual que protege la propiedad latifundista adquirida antes de la elaboración y reglamentación de la nueva CPE (2009). Este artículo estipula que dichas propiedades, tituladas o no, están protegidas siempre y cuando demuestren el cumplimiento 
de la función económica y social de la tierra, proceso que, al igual que el de titulación y saneamiento, quedó paralizado.

Es importante, sin embargo, entender estos procesos dentro de los ritmos del momento sociopolítico que los caracterizaron, pues la constitucionalización de casi la totalidad del latifundio del país expresa con claridad la priorización de la consolidación de poder del gobierno a través de su vinculación y alianza con las élites del agronegocio.

En este momento, y como era de esperarse, el sector agroindustrial había encontrado en la nueva legislación un respaldo gubernamental que no solo promovía el crecimiento del sector productivo, sino abonaba permanentemente sus objetivos, afirmando en más de una ocasión que se modificaría y eliminaría lo que fuera necesario para "potenciar" aún más este sector. En este marco, las principales organizaciones terratenientes del país (CAO, ANAPO, FEGABENI, CONFEAGRO, FUNDACRUZ, entre otras) comenzaron a presionar para que se introdujeran nuevas variedades transgénicas -además de la soya- al país, usando entre sus argumentos la responsabilidad del gobierno de priorizar y garantizar la seguridad alimentaria, y también haciendo un énfasis sobre la inexistencia de evidencias oficiales sobre el daño de los transgénicos en la salud (Ormachea y Ramírez, 2013).

A este respecto, es necesario resaltar que la producción de este sector está prácticamente en su totalidad avocada a la exportación, dentro de lo que el departamento de Santa Cruz -el más importante en cuanto a tierras productivas, y también el más sembrado con soya- es un caso particular, pues exporta el $70 \%$ de su producción agrícola, y aporta muy poco a la seguridad alimentaria del país (Salazar, 2015).

Sin embargo, a pesar de la claridad con que se desarrollaba el ensamblaje entre el bloque terrateniente dominante y el gobierno, en el año 2011, este dio un paso trascendental que podría ser leído como uno de los más importantes eslabones del favorecimiento a las estructuras de dominación y el capital transnacional: la autorización legal para la introducción de paquetes tecnológicos transgénicos que no vulneren aquellas especies de las que "Bolivia es centro de origen o diversidad, ni aquellas que atenten contra el patrimonio, la biodiversidad, la salud de los sistemas de la vida y la salud humana", establecido en el Art. 15 de la Ley de Revolución Productiva Comunitaria Agropecuaria (Ley N. ${ }^{\circ}$ 144) (Bolivia, 2011).

Esta autorización, también negociada en el Congreso el año 2009, establece en el Art. 409 de la nueva CPE, que "La producción, importación y 
comercialización de transgénicos será regulada por Ley” (Bolivia, 2009), por lo que actualmente en Bolivia, al igual que en el resto de países de la región, el único cultivo transgénico autorizado legalmente es la soya, producto predilecto del sector agroindustrial.

\section{Vertiginosa expansión soyera y devastación ambiental irrestricta}

Según el Instituto Nacional de Estadísticas (INE, 2013), la superficie total cultivable en Bolivia es de 3.631.508 millones de hectáreas, de las cuales, en datos preliminares al 2015, un total de 1,350.000 millones de hectáreas están siendo ocupadas con soya, un $37.18 \%$ de la tierra cultivable del país.

Los efectos del favorecimiento al sector agroindustrial pueden ser evidenciados en las cifras presentadas por ANAPO (2013) que reflejan con claridad que el primer año de gestión del actual gobierno (2006), la producción de soya transgénica representaba aproximadamente el $20 \%$ del total de la soya producida en el país, es decir, ocupaba un total de 180.556 ha. de las 947.783 ha. en que se cultivaba dicha oleaginosa. Sin embargo, para el año 2011-2012 la soya transgénica llegó a representar el $98 \%$ de la producción total de soya, habiendo en ese entonces alcanzado un hito al sobrepasar el millón de hectáreas (Ormachea y Ramírez, 2013).

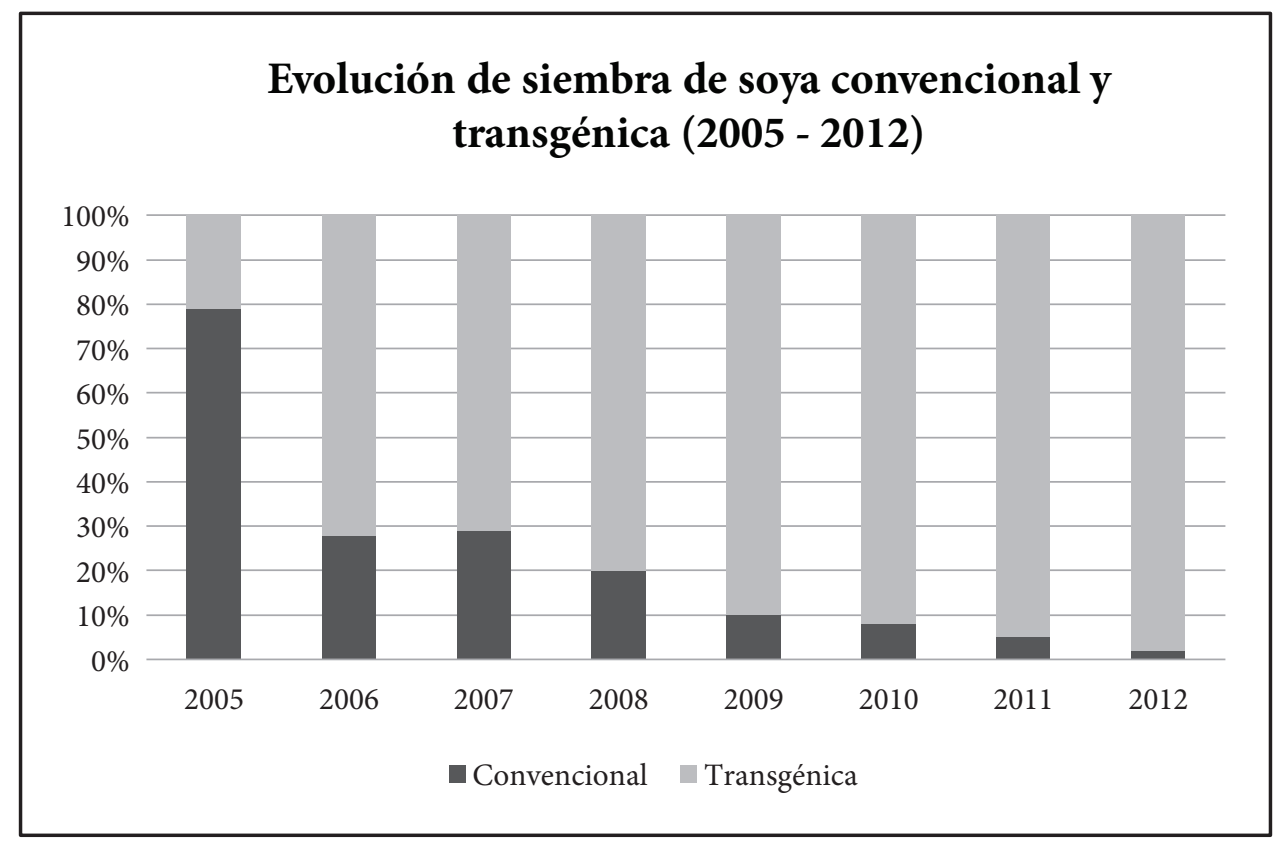

Figura 2. Evolución de siembra de soya convencional y transgénica en Bolivia entre los años 2005 y 2012. Elaboración propia con datos de ANAPO (2013). 
Paradójicamente, a finales del 2012, el gobierno promulgó la Ley Marco de la Madre Tierra (Ley N. ${ }^{\circ} 300$ ) que despertando mucha polémica, proponía una serie de fundamentos sociales y de relación con la Madre Tierra, que más allá de las críticas a la promoción del desarrollismo que en esta se desliza, enuncia en su Art. 24 que se deben "desarrollar acciones que promuevan la eliminación gradual de cultivos de organismos genéticamente modificados autorizados en el país a ser determinados en norma específica” (Bolivia, 2012). Esta ley, y específicamente este artículo, despertó una vez más una serie de conflictos en el sector agroindustrial, frente a lo que el gobierno no tardó en manifestar su apoyo y protección incondicional tanto para el sector, como para su demanda, que en este caso eran explícitamente los transgénicos.

Hasta el momento, dicha ley no ha sido reglamentada, lo que posibilita también el crecimiento vertiginoso de la expansión de cultivos de soya transgénica en el país (Ver Figura 3), que no hubiera sido posible sin la explícita identificación del gobierno con los intereses del sector agroindustrial, el cual, en tanto cúpula de poder aliada, ha avanzado sistemáticamente en la legalización de todas aquellas actividades históricas de despojo y devastación medio ambiental que actualmente permiten la monopolización de tierras (Ormachea y Ramírez, 2013).

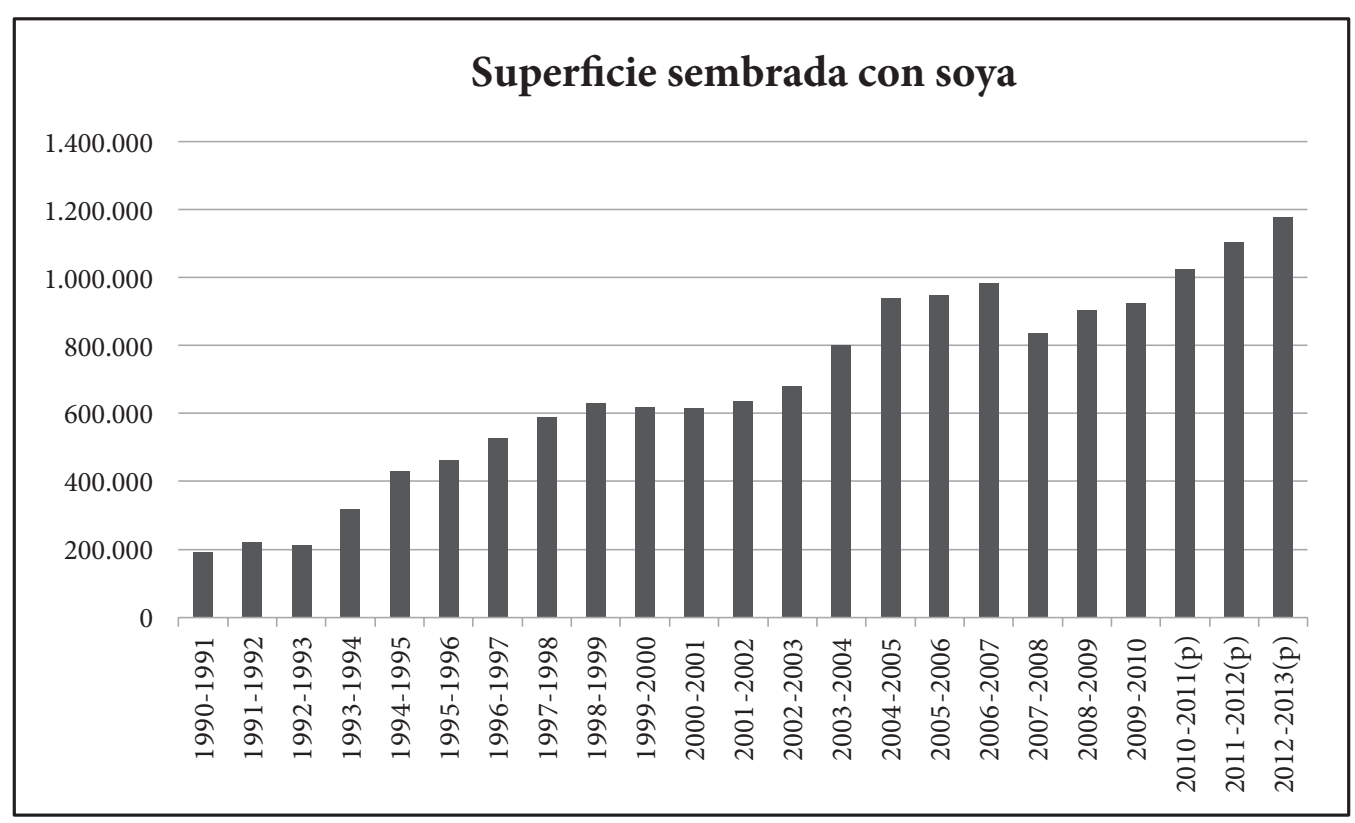

Figura 3. Crecimiento de la superficie sembrada con soya en Bolivia entre los años 1990 y 2013. Elaboración propia con datos de Instituto Nacional de Estadística (INE).

Sin embargo, es preciso volcar la mirada sobre las implicancias de la constante y veloz expansión de la frontera agrícola, que en 2013 fue impulsada a 
través de la Ley de Apoyo a la Producción de Alimentos y Restitución de Bosques (Bolivia,2013 ), que, a pesar de su denominativo, es más conocida en el país como Ley de Desmontes ${ }^{3}$ (Ley N. ${ }^{\circ} 337$ ), pues ha legalizado la conversión ilegal de tierras de cobertura boscosa en tierras de uso agrícola y pecuario desde 1996 hasta 2011.

Esta ley, como pretende mostrar su nombre, fue promulgada con el argumento de incrementar la producción de alimentos, aunque, dado que dichas tierras ya se encontraban produciéndolos y eran en su mayoría para la exportación agroindustrial, queda claro que su función fue la protección del sector latifundista que había realizado desmontes ilegales, y que, por tanto, corría el riesgo de que su propiedad sea revertida.

A este respecto, es primordial añadir que, según el Instituto Nacional de Innovación Agropecuaria y Forestal (INIAF, citado en Salazar, 2015), en el periodo señalado (1996 - 2011), la deforestación ilegal alcanzó un total de 5.5 millones de hectáreas, de las cuales $38 \%$ son pertenecientes al sector ganadero, el $28 \%$ al sector agroindustrial, el $17 \%$ al colonizador extranjero, el $12 \%$ al campesino, y finalmente el 5\% al indígena. A pesar de significar esto una invaluable pérdida y riesgo tanto a nivel ecológico como social, fueron legalizadas y consideradas tierras con una función económica y social, garantizando una vez más la reproducción de la estructura patrimonialista de tenencia de la tierra como propiedad privada.

3 Bautizada y conocida nacionalmente como "perdonazo agrícola" o "perdonazo forestal" por ser un instrumento que permite y legaliza los desmontes y deforestación ilegal penalizadas por la legislación tanto agraria como forestal actualmente vigentes. 


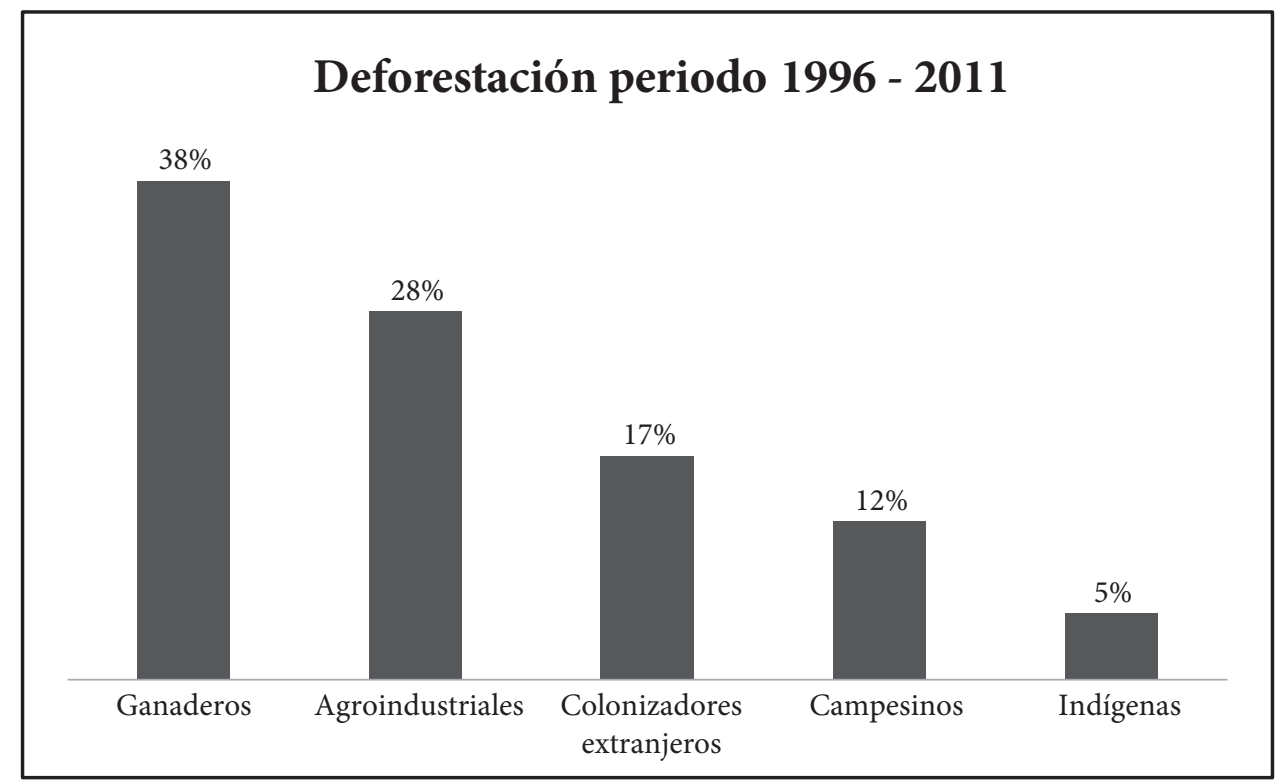

Figura 4. Deforestación en Bolivia en el periodo 1996 - 2011. Elaboración propia con datos de Salazar (2015).

No obstante, el proceso de consolidación de la alianza Estado - oligarquía terrateniente tiene un último evento importante: la "Cumbre Agropecuaria: Sembrando Bolivia", llevada a cabo a principios del año 2015. En esta, la Asociación de Productores de Oleaginosas y Trigo (ANAPO) y demás asociaciones agroindustriales demandaron la "autorización de la ampliación de uso de "biotecnología" en semillas transgénicas para la producción de maíz, algodón, y caña de azúcar", con la finalidad de incrementar la competitividad de dichos productos (La Razón, 2015). Asimismo, se ha propuesto ampliar aún más el plazo de verificación de la FES, continuar la titulación y saneamiento de los grandes latifundios, y seguir impulsando la ampliación de la frontera agrícola para la producción agroexportadora que, una vez más, se encuentra muy alejada de la seguridad alimentaria del país (CFB, 2015).

En la actualidad, y desde mediados del 2016, el bloque oligarca dominante del que se ha tratado en este artículo, junto a una gran mayoría de las instituciones de comercio y exportación, ha iniciado una nueva, controversial y nociva demanda: la importación de maíz transgénico. Esta, por su intensidad, a pesar de contravenir la legislación existente expuesta anteriormente, ha generado un ambiente de tensas pugnas de las cuales aún no se tienen resultados, pero que, sin lugar a duda, determinarán el devenir del sector agropecuario, campesino e indígena del país. 


\section{Reflexiones finales}

Actualmente, y con el cada vez más intenso debilitamiento y desarticulación de las organizaciones sociales populares producto de los procesos anteriormente expuestos, no existe una base material que permita dialogar sobre las reivindicaciones sociales populares, pues estas han quedado entrampadas - pero no absorbidas- en una retórica y una estética expropiadas de las luchas históricas y sus narrativas por el partido de gobierno (Gutiérrez y Salazar, 2013).

El sistemático vaciamiento de significación de estas narrativas sociales populares ha neutralizado símbolos, prácticas y discursos para dar lugar a una reconstrucción del orden de dominación hegemónico y expansión del poder capitalista, lo que se refleja en la expansión de la soya transgénica en la región de Santa Cruz. De esta manera, y haciendo uso de un discurso diametralmente opuesto al del neoliberalismo, el actual gobierno ha logrado mimetizar la adopción de los objetivos del gran capital, e introducirlas efectivamente en los diversos entramados sociales, garantizando así la generación de condiciones que favorezcan la reproducción del capital (Tapia, 2014).

El "proceso de cambio" ha reconstituido y consolidado la jerarquización de un orden social, político y económico consonante con el modelo de desarrollo del capitalismo moderno, que a nombre del progreso económico (que en este periodo se debió únicamente al incremento de los precios internacionales de las materias primas, que ahora se encuentran en descenso), es ajeno e indiferente a las históricas luchas sociales y ecológicas. En este marco, la introducción del uso de "biotecnología" responde a un proyecto económico y de Estado de protección de las élites en tanto aliadas, y desposesión del sector popular, indígena y campesino del país.

Así, la exhaustiva revisión y análisis realizado de las dinámicas y entramados sociopolíticos alrededor de la tierra como condición básica para la producción de transgénicos en Bolivia permiten comprender y afirmar que las múltiples transformaciones y metamorfosis de la política estatal boliviana han anulado, en su totalidad, la posibilidad de una transformación productiva desde el Estado. Al contrario, como se ha podido evidenciar a lo largo del proceso analizado, el marco legal del conflicto de tierras en Bolivia en el que los transgénicos son un eje angular ha puesto a la tierra y a su producción al servicio de los objetivos del capital nacional y transnacional (Gutiérrez y Salazar, 2013). 
No obstante, no debe perderse de vista la tenacidad de la fuerza y las pugnas sociales emancipatorias desde las cuales se ha leído este proceso. Las posibilidades de transformación son tan heterogéneas como las dinámicas de los entramados de las luchas sociales populares, que de diversas maneras han configurado y reconfigurado los compases y devenir de la historia de Bolivia. Así, el reto actual pasa por recuperar la fortaleza y rehabitar las luchas históricas por fuera -y si es necesario, a espaldas- del Estado, como una forma de organizar la esperanza del presente, para germinación de un futuro.

\section{Referencias}

Asociación de Productores de Oleaginosas y Trigo (ANAPO). (2013). Anuario Estadístico 2012. Santa Cruz: ANAPO.

Bolivia. 2013. Ley de Apoyo a la Producción de Alimentos y Restitución de Bosques (Ley N. ${ }^{\circ} 337$ ). Autor.

Bolivia. (2009). Constitución Política del Estado Plurinacional de Bolivia (CPE). Autor.

Bolivia. (2011). Ley de Revolución Productiva Comunitaria Agropecuaria (Ley N. ${ }^{\circ}$ 144). Autor.

Bolivia. (2012). Ley Marco de la Madre Tierra (Ley N. $\left.{ }^{\circ} 300\right)$. Autor.

Cámara Forestal de Bolivia (CFB). (2015). Mesa 1. Tierra y Estructura Agraria. Cumbre Agropecuaria Sembrando Bolivia. Recuperado de http:// www.cfb.org.bo/noticias/economia-comercio/mesa-1-tierra-y-estructura-agraria-cumbre-agropecuaria-sembrando-bolivia

Centro para la Investigación Forestal Internacional (CIFOR). (2014). El contexto de la deforestación y degradación de los bosques en Bolivia: Causas, actores e instituciones (Documentos ocasionales 100). Bogor, Indonesia: CIFOR. Recuperado de http://www.cifor.org/publications/pdf_files/ OccPapers/OP-100.pdf

García, Álvaro. (2014). García Linera, el M.A.S. y los terratenientes del Oriente (Vídeo). Recuperado de https://www.youtube.com/watch?v=9oWtM6a rFWk\&list $=$ WL\&index $=18$.

Gutiérrez, Raquel. (2009). Los ritmos del Pachakuti. Levantamiento y movilización en Bolivia (2000-2005). México: Sísifo/Bajo Tierra/ICSH. 
Gutiérrez, Raquel y Salazar, Huascar. (2013). El accidentado camino del buen vivir: Horizontes indígena-originario-campesinos en Bolivia durante el gobierno de Evo Morales. Revista ALASRU, 7.

Instituto Nacional de Estadística (INE). (2013). Estadísticas por actividad económica: Superficie cultivada, por año agrícola, según cultivo. Recuperado de: http://www.ine.gob.bo/indice/general.aspx?codigo=40104

INRA. (2010). Breve historia del reparto de tierras en Bolivia. La Paz: INRA.

La Razón. (2015). Anapo propone ampliar uso de la biotecnología a 3 productos. Recuperado de http://www.la-razon.com/economia/Anapo-propone-ampliar-biotecnologia-productos_0_2235376489.html

Molina, Patricia. (2011). Ante la falta de políticas agropecuarias en Bolivia: Transgénicos por encargo. Recuperado de http://www.bolpress. $\mathrm{com} /$ ?Cod=2011060908

Ormachea, Enrique. (2007). ¿Revolución agraria o consolidación de la vía terrateniente? El gobierno del MAS y las políticas de tierras. La Paz: CEDLA.

Ormachea, Enrique y Ramírez, Nilton. (2013). Políticas agrarias del gobierno del MAS o la agenda del "poder empresarial-hacendal. La Paz: CEDLA.

Salazar, Huascar. (2015). Se han adueñado del proceso de lucha. Horizontes comunitario-populares en tensión y la reconstitución de la dominación en la Bolivia del MAS. Cochabamba, Bolivia: SOCEE.

Soruco, Ximena. (2008). Los barones del Oriente. El poder en Santa Cruz ayer y hoy. Santa Cruz: Fundación Tierra.

Tapia, Luis. (2011). El estado de derecho como tiranía. La Paz: CIDES/UMSA.

Tapia, Luis. (2014). La relación entre gobierno y movimientos indígenas en el ciclo de cambio político en Bolivia. En Fabiola Escárzaga, Raquel Gutiérrez, Juan Carrillo, Eva Capece y Böerries Nehe (Eds.), Movimiento indígena en América Latina: Resistencia y transformación social (Vol. III). México: UAM-X/ICSyH/CIESAS.

Urioste, Miguel. (2009). Balance de la reforma agraria en Bolivia. La reforma agraria inconclusa. Fundación Tierra Bolivia post-constituyente. Tierra, territorio y autonomías indígenas. Memoria seminario internacional. La Paz: Fundación TIERRA. 